\title{
O ENSINO DE SOCIOLOGIA RETRATADO NAS TESES E DISSERTAÇÕES ENTRE 1996 E 2015: UMESTADO DA ARTE
}

\author{
Katiuscia Vargas Antunes ${ }^{1}$ \\ Edmar Augusto Semeão Garcia ${ }^{2}$ \\ Amanda Fontes Alves ${ }^{3}$
}

\section{Resumo}

Este trabalho tem como finalidade apresentar os resultados do projeto de pesquisa "Estado da arte do ensino de Sociologia na Educação Básica: o que dizem as dissertações e teses sobre o tema", apoiado pelo Programa de Iniciação Científica BIC/UFJF. O objetivo central foi realizar uma investigação do tipo estado da arte das produções acadêmicas no campo da pós-graduação strictu senso, analisando dissertações e teses que abordam a temática do ensino de Sociologia no Ensino Médio. A pesquisa se orientou pelos pressupostos da investigação do tipo estado da arte, conforme descrito por André et al (1999). Nossas estratégias consistiram em: $\left.1^{\circ}\right)$ mapear e quantificar a produção sobre ensino de Sociologia, no período 1996 a 2015; 2) categorizar e descrever a produção encontrada e $3^{\circ}$ ) analisar e (re)escrever a história da consolidação da Sociologia como disciplina escolar e do ensino de Sociologia como campo de pesquisa no Brasil. Apesar das pesquisas do tipo estado da arte sofrerem críticas em relação ao seu alcance, por se valerem, muitas vezes, de uma leitura parcial dos trabalhos, concordamos com Handfas e Maçaira (2014) ao afirmarem que a pertinência de pesquisa como a que apresentamos aqui, se dá pela necessidade de conhecermos a construção de um campo de estudos, neste caso, o do ensino de sociologia na escola básica.

Palavras-chave: Estado da arte, Ensino de Sociologia, Educação Básica.

\section{THE TEACHING OF SOCIOLOGY PORTRAITED IN THESES AND DISSERTATIONS BETWEEN 1996 AND 2015: A STATE OF ART}

\section{Abstract}

This paper aims to present the results of the research project "State of the Art

\footnotetext{
1 Professora Adjunta do Departamento de Educação. Faculdade de Educação. FACED/UFJF

2 Bacharel em Ciências Humanas e Ciências Sociais.

${ }^{3}$ Graduanda em Ciências Sociais pela UFJF
} 
of Teaching Sociology in Basic Education: what the dissertations and theses on the subject say", supported by the BIC / UFJF Scientific Initiation Program. The central objective was to carry out a state-of-the-art research of academic productions in the field of strictu senso graduate studies, analyzing dissertations and theses that deal with the teaching of Sociology in High School. The research was guided by the assumptions of state-of-the-art research, as described by André et al (1999). Our strategies consisted of: 1) mapping and quantifying the production of sociology teaching, from 1996 to 2015; 2) to categorize and describe the production found; and 3) to analyze and (re) write the history of the consolidation of Sociology as a school discipline and of the teaching of Sociology as a field of research in Brazil. Although state-of-the-art surveys are criticized in terms of their reach, often relying on a partial reading of the works, we agree with Handfas and Maçaira (2014) in stating that the pertinence of research such as the one presented here, is due to the need to know the construction of a field of studies, in this case, the field of sociology teaching in the basic school.

Key-Words: State of the Art; Teaching Sociology; Basic Education.

\section{Apresentação}

O Ensino de Sociologia no contexto do Ensino Médio vem se consolidando no sistema educacional brasileiro, após a promulgação da lei que torna a disciplina de Sociologia obrigatória nos currículos de todas as séries do Ensino Médio (BRASIL, 2008).

Entre os professores que atuam com esta disciplina, não há uma orientação didático-metodológica que norteie o fazer pedagógico. Não há, também, no campo da Sociologia, um consenso em relação a que conteúdos devem ser trabalhados com os jovens. Embora tenham sido elaboradas as Orientações Curriculares Nacionais para o Ensino Médio (BRASIL, 2006), o caderno que trata do Ensino de Sociologia, não traz com clareza os conteúdos e habilidades que devem ser desenvolvidas. Importa dizer, ainda, que estamos em vias de aprovação da Base Nacional Curricular Comum - BNCC para o Ensino Médio e, este documento, em que pese todas as críticas que vem sendo tecidas a respeito de seu processo de elaboração, procura apresentar de forma mais objetiva os conteúdos a serem trabalhados em Sociologia nas séries que compõem o ensino médio. Mesmo diante desses processos de organização curricular, a Sociologia ainda se configura numa disciplina marginal, pois mesmo diante da sua, até então, obrigatoriedade, ocupa um tempo mínimo de 50 minutos semanais na carga horária dos estudantes.

Nesse contexto de intermitência da presença/ausência da sociologia nos 
currículos escolares e do seu, ainda, processo de institucionalização, nos propusemos a investigar como a temática do ensino de sociologia na escola básica vem sendo pesquisada nos programas de pós-graduação de universidades brasileiras.

No intuíto de ampliar o conhecimento acerca da consolidação do ensino de Sociologia no Brasil esta pesquisa teve como objetivo realizar uma investigação do tipo estado da arte das produções acadêmicas no campo da pós-graduação strictu senso, analisando dissertações e teses que abordam a temática do ensino de Sociologia no Ensino Médio.

A proposta de pesquisa surgiu a partir dos encontros do projeto de Iniciação à Docência - PIBID/Ciências Sociais. Nas reuniões de estudo sentimos a necessidade de expandir o arcabouço teórico sobre o ensino de Sociologia, tendo uma visão mais ampliada deste campo de estudo que, por ser relativamente recente, ainda se configura num espaço aberto para investigações de diferente natureza.

Na discussão acerca dos resultados que consolidamos, procuramos fazer uma relação destes com outros estudos do tipo estado da arte que foram produzidos por outros pesquisadores do campo, dentre os quais podemos citar os trabalhos de Handfas e Maçaira (2014); Handfas (2011) e Oliveira (2013).

A seguir, apresentaremos a metodologia que norteou a pesquisa.

\section{Percurso metodológico}

A pesquisa se orientou pelos pressupostos da investigação do tipo estado da arte, conforme descrito por André et al (1999). Nos últimos quinze anos, tem-se produzido um conjunto significativo de pesquisas conhecidas pela denominação "estado da arte" ou "estado do conhecimento". Frigotto e Ciavatta (2006) apontam que os "estados da arte" têm tradição pequena no Brasil e que, com o crescimento da produção científica a partir de 1990, eles se tornaram uma necessidade, visto que permitem o "mapeamento do conhecimento produzido, das questões emergentes ou ainda abertas à pesquisa - o que implica um inventário do que se produziu no período de tempo que se deseja investigar ou ter como ponto de partida para novos estudos" (p.71).

Considerando-se essas pesquisas, acreditamos que nossa proposta ajustase à perspectiva metodológica que vem sendo desenvolvida pelas mesmas, sustentando: (1) uso de uma metodologia de caráter inventariante e descritivo 
da produção acadêmica e científica sobre o tema que se busca investigar; (2) mapeamento e categorização da produção a partir de suas características, definindo os trabalhos individualmente e no conjunto; (3) identificação e análise dos aspectos e dimensões que vêm sendo destacados e privilegiados em determinado período e local e (4) verificação e análise das formas e condições em que têm sido produzidas as pesquisas.

Baseando-nos no trabalho de André et al (1999), que entende o "estado da arte" como uma síntese integrativa do conhecimento sobre um tema, optamos por considerar as produções do tipo dissertações e teses produzidas nos programas de pós-graduação das diferentes universidades brasileiras. Portanto, entendemos que esta metodologia de caráter inventariante e descritivo nos permitiu analisar as produções e, assim, atingir os nossos objetivos.

Iniciamos a pesquisa fazendo uma busca no banco de teses e dissertações da CAPES, delimitando a pesquisa a partir dos seguintes descritores: ensino de sociologia; sociologia e ensino médio e currículo de sociologia. Essa primeira busca no levou a outras bases de dados, como por exemplo, os sites dos programas de pós-graduação onde os trabalhos foram defendidos e alguns sites de laboratórios de ensino de sociologia que abrigavam informações sobre teses e dissertações defendidas no campo do ensino de sociologia. Os trabalhos encontrados foram baixados na íntegra, catalogados em fichas de análise específicas para posterior análise.

Realizamos um primeiro levantamento quantitativo de todos os trabalhos encontrados e, posteriormente à análise de cada produção, chegamos a algumas categorias temáticas que retratam qualitativamente a discussão central de cada pesquisa. No total foi possível elaborar seis categorias, a saber: 1) Currículo de Sociologia na escola básica; 2) Formação de professores de Sociologia; 3) Recursos didático-metodológicos; 4) Institucionalização da Sociologia como disciplina escolar; 5) Práticas pedagógicas no Ensino de Sociologia e 6) Sociologia da Educação.

Na seção a seguir, apresentaremos os resultados deste estudo.

\section{O que nos dizem as dissertações e teses sobre o ensino de sociologia no Brasil}

Passaremos agora a apresentar os resultados que este estudo produziu a partir do levantamento e análise das dissertações e teses sobre ensino de sociologia 
entre os anos de 1996 e 2015. No que se refere aos dados quantitativos, foi possível identificar e catalogar 59 trabalhos $^{4}$, sendo 49 dissertações e 10 teses. O gráfico a seguir apresenta a distribuição do quantitativo de trabalho por ano.

Gráfico 1 - Dissertações e teses por ano de publicação

\section{Dissertação e Tese/Ano}

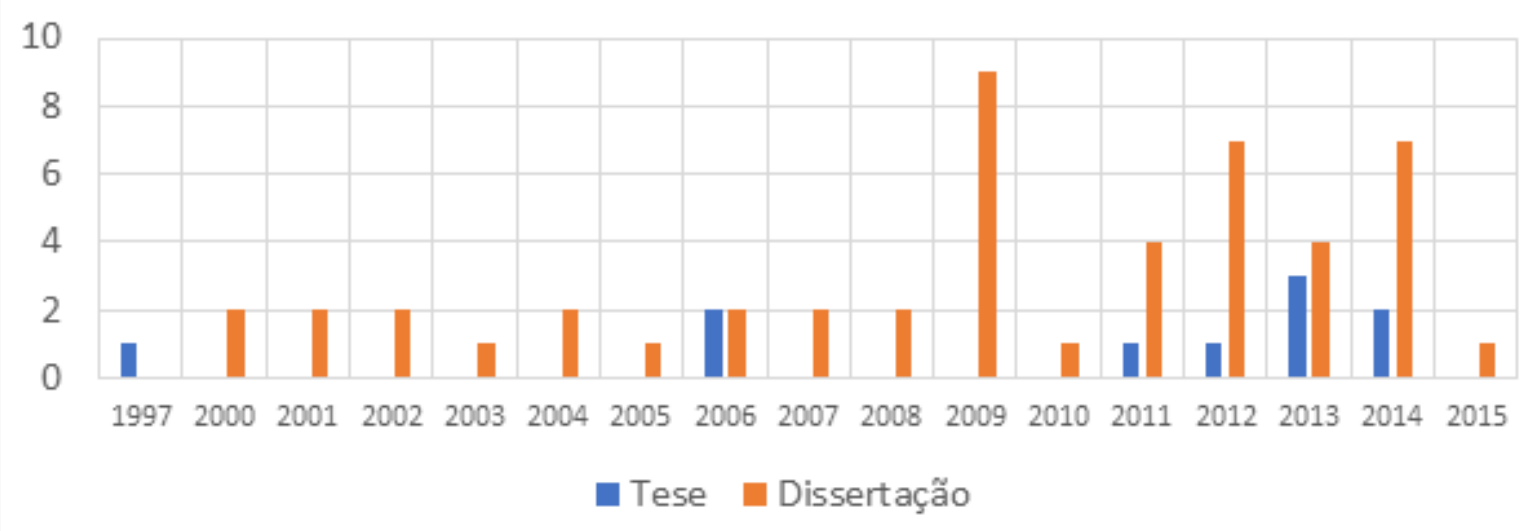

Fonte: Dados organizados pelos autores.

O gráfico 1 nos dá uma visão geral das dissertações e teses por ano de publicação. O que podemos perceber é que há um crescimento significativo no número de trabalhos sobre a temática do ensino de sociologia no ensino médio a partir do ano de 2009. Tal fato pode se justificar pela presença obrigatória da sociologia nos currículos escolares a partir de 2008. Esse episódio abre um campo de pesquisa amplo para aqueles que se voltam para investigar como a sociologia vem se institucionalizando na escola básica.

Importa ressaltar que pesquisas que visam construir um estado da arte das produções no campo do ensino de sociologia já vêm ocorrendo desde 2003, quando pesquisadores do campo das Ciências Sociais e da Educação já se voltavam para esse estudo (MORAES, 2003; SILVA, 2003; MAÇAIRA, 2010). Um ponto a ser destacado é que nas pesquisas do tipo estado da arte já realizadas sobre a temática que se dedica este artigo não apresentam uma uniformidade de dados em relação ao quantitativo de trabalhos registrados. Segundo Handfas (2011),

\footnotetext{
${ }^{4}$ Encontramos mais 8 trabalhos, mas não tivemos acesso aos arquivos e, portanto, não utilizamos como dado de pesquisa.
} 
o desequilíbrio nos levantamentos já realizados pode se justificar pelo fato de que o espaço de tempo entre cada um deles é relativamente grande, acabando por evidenciar um panorama diferenciado sobre a produção de pesquisas sobre ensino de sociologia.

Outro dado quantitativo que nos chamou atenção foi com relação a concentração das produções por região. Conforme demonstra o gráfico 2, o maior número de trabalhos foi realizado nas regiões Sudeste (26), seguida da região Sul (20).

Gráfico 2 - Dissertações e teses por região

\section{Dissertações e Teses/Região}

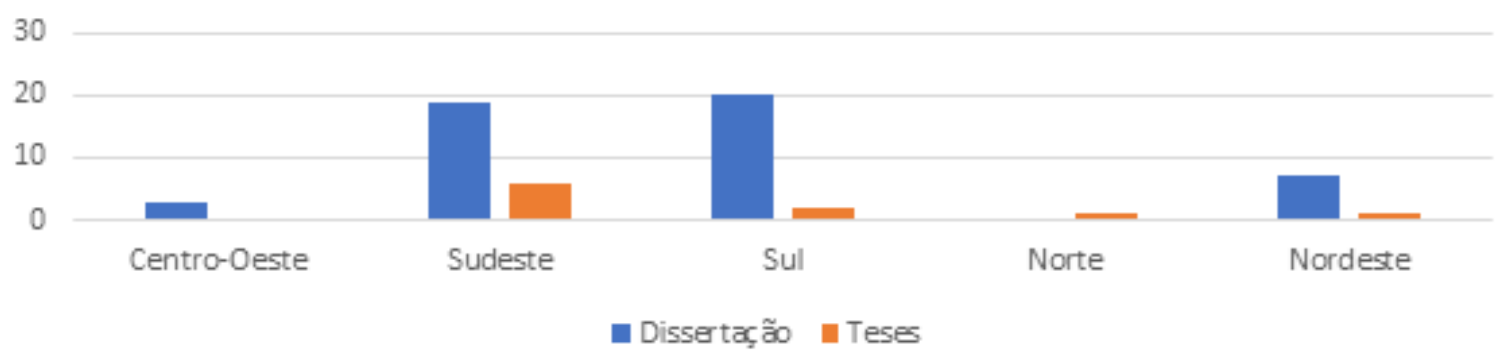

Fonte: Dados organizados pelos autores.

O dado mostrado no gráfico 2 nos confirma a concentração de produção no eixo Sul-Sudeste, corroborando com estudos antes realizados que, assim como este, mostram que as universidades dessas regiões vêm concentrando o maior número de produções sobre ensino de sociologia. O estudo realizado por Handfas (2011) demonstrou que o maior quantitativo das produções acadêmicas está nos Estados do Rio de Janeiro, São Paulo e Paraná. Podemos dizer que tal panorama está diretamente relacionado com o fato da comunidade acadêmica das instituições públicas de ensino superior das regiões Sul e Sudeste ter se implicado mais diretamente com as questões teóricas e práticas do ensino de sociologia.

Com relação ao número de trabalhos por programas de pós-graduação, A partir do podemos perceber pelo gráfico 3 que a maioria dos trabalhos localizados são vinculados a Programas de pós-graduação em Educação, perfazendo um total de 29 trabalhos, seguidos de 26 trabalhos nos programas de pós-graduação em 
sociologia e em Ciências Sociais.

Gráfico 3 - Dissertações e teses por programa de pós-graduação

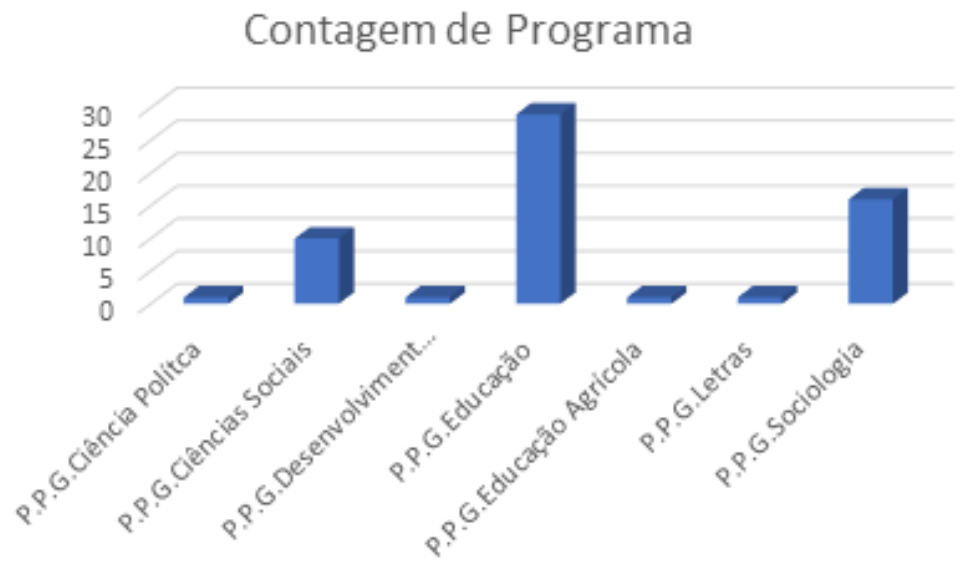

Fonte: Dados organizados pelos autores.

Esse panorama nos permite dizer que as questões relacionadas à sociologia como saber escolar e a formação de professores para atuarem no ensino médio vem gradativamente ocupando um espaço maior no campo das Ciências Sociais, mesmo havendo um número maior de trabalhos na educação. Tal fato sinaliza para uma reflexão importante acerca da formação no âmbito dos cursos de graduação em Ciências Sociais: se o número de pesquisas com o tema ensino de sociologia vem crescendo na pós-graduação, por que essa realidade não reflete na reconfiguração da graduação, na medida em que ainda verificamos uma supervalorização do bacharelado em detrimento da licenciatura? Os professores que vem atuando no ensino médio brasileiro estão sendo formados, ainda, num modelo em que a licenciatura ocupa um lugar marginal se considerarmos a sua relação com a formação do bacharel em Ciências Sociais, reforçando a dicotomia histórica entre bacharelado e licenciatura.

Outro interesse nesta pesquisa foi procurar identificar as metodologias utilizadas nos trabalhos. Observamos que a metodologia predominante nas pesquisas foi do tipo revisão bibliográfica, contabilizando 22 estudos. Em 
O ensino de Sociologia retratado nas teses e dissertações entre 1996 e 2015, pp. 287 - 298

seguida aparecem a análise documental (19) e a observação participante (15). É importante ressaltar que em todos os trabalhos verificamos uma associação de diferentes recursos de produção de dados, como por exemplo, a observação participante e a utilização de entrevistas ou questionários. Como se pode perceber, as metodologias recorrentes fazem parte do contexto das pesquisas qualitativas, de cunho exploratório.

Gráfico 5 - Tipos de Metodologia utilizada nas pesquisas

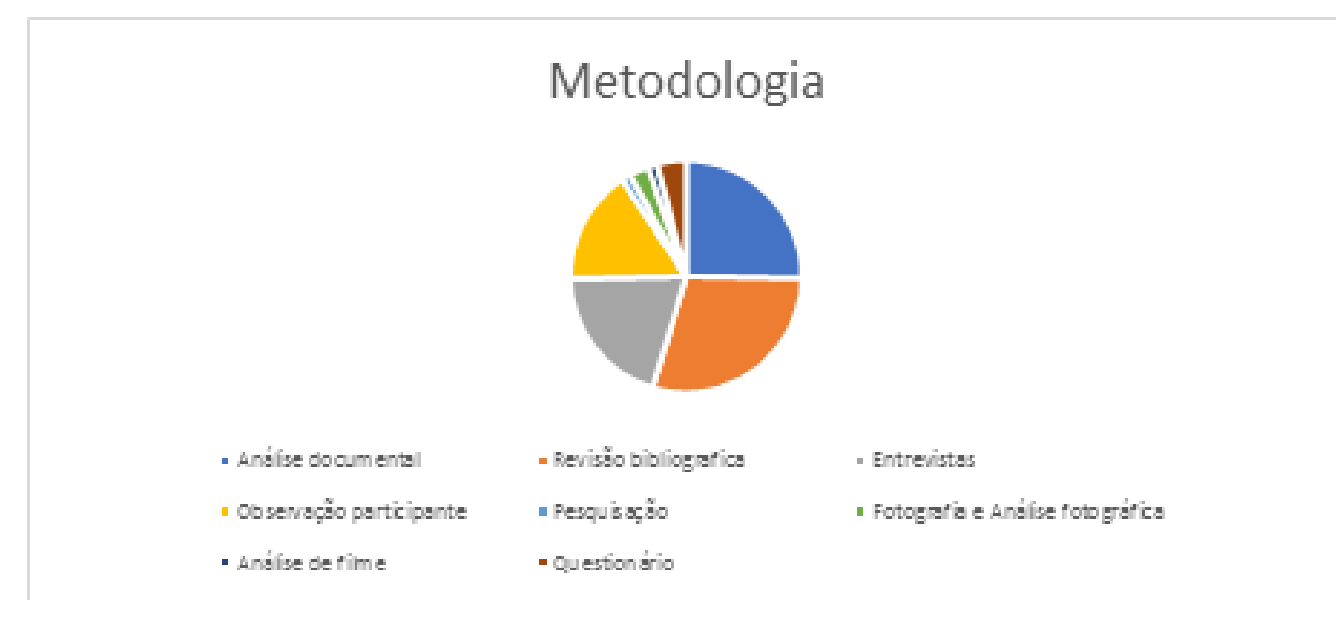

Fonte: Dados organizados pelos autores

No que se refere a categorização dos trabalhos pelas temáticas mais recorrentes, os resultados parciais nos permitem organizar as pesquisas em, pelo menos, seis temáticas, a saber: Currículo de sociologia na escola básica (23); Formação de professores de sociologia (12); Recursos didático-metodológicos (10); Institucionalização da sociologia como disciplina escolar (08); Práticas pedagógicas no Ensino de sociologia (04); e Sociologia da Educação (02)

Gráfico 6 - Dissertações e teses por área temática

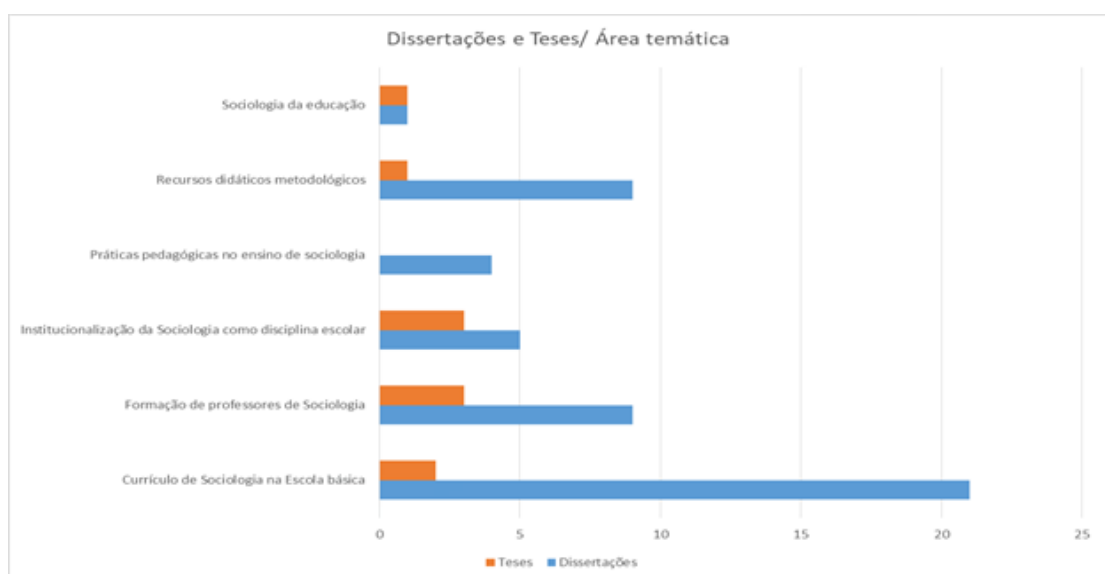

CSOnline - Revista Eletrônica de Ciências Sociais, Juiz de Fora, n. 28 (2019) 
Fonte: Dados organizados pelos autores.

Pelos dados apresentados, já é possível constatar que existe uma grande preocupação por parte dos pesquisadores no que se refere à consolidação da sociologia como disciplina escolar, especialmente no que toca as discussões sobre o currículo de sociologia no Ensino Médio. Essa tendência se justifica, entre outras razões, pelo fato de que a sociologia vigora nos currículos do Ensino Médio há apenas 8 anos, sendo, ainda, necessário criar uma identidade para esta disciplina, definindo qual é o seu papel na formação dos jovens.

No estudo realizado por Handfas e Maçaira (2012) a análise das dissertações e teses entre os anos de 1993 a 2012 também demonstrou um maior número de trabalhos no campo do currículo. Como nossa pesquisa avança em relação ao ano de 2013, se estendendo até 2015, podemos dizer que tal tendência só vem crescendo ao longo dos anos. Nossa hipótese é que tal crescimento poderá ser ainda maior tendo em vista os acontecimentos que atravessam o ensino de sociologia na escola básica no último ano, quais sejam: a formulação da Base Nacional Curricular Comum - BNCC e a famigerada Reforma do Ensino Médio, que coloca em risco a presença da sociologia no ensino médio.

A formação de professores de sociologia foi a segunda categoria mais recorrente, demonstrando que esta tem sido uma preocupação de pesquisadores que se dedicam a investigar o ensino de sociologia na escola básica no Brasil. Como mencionado em outro momento deste artigo, a formação de professores de sociologia no Brasil enfrenta um debate histórico sobre a relação entre bacharelado e licenciatura, sendo esta última delegada a uma posição de menos prestígio no contexto da formação na graduação. Por outro lado, sabemos que nos últimos anos o maior campo de trabalho para os egressos dos cursos de Ciências Sociais tem sido as escolas de educação básica públicas e privadas do país. Tal fato nos sinaliza para a necessidade de se pensar como os cursos de Ciências Sociais vem lidando (ou evitando) lidar com a realidade de formar professores, também, para atuarem na escola básica.

\section{Considerações Finais}

O objetivo deste trabalho foi apresentar os resultados da pesquisa sobre o estado da arte das dissertações e teses sobre ensino de sociologia produzidas nos programas de pós-graduação das universidades brasileiras entre os anos de 
1996 a 2015.

O levantamentorealizadosebaseou nabusca pelas produções no banco deteses e dissertações da CAPES como fonte principal de pesquisa. Secundariamente fizemos a busca dos trabalhos nos sites dos programas de pós-graduação e nos sites de alguns laboratórios de ensino de sociologia. Encontramos um total de 67 trabalhos, entretanto, só conseguimos ter acesso ao texto na íntegra de 59 produções. Por impossibilidade de fazer uma análise mais apurada dos oito trabalhos que não foram encontrados na íntegra, optamos por descarta-los.

Este estudo tem se revelado para nós de grande relevância para o campo das Ciências Sociais. Ao longo do período estudado identificamos que os programas de Ciências Sociais começaram a admitir pesquisa no campo do ensino de sociologia e da formação de professores para a educação básica. Assim como Handfas e Maçaira (2012), nós chegamos à conclusão de que os resultados apresentados neste estudo ajudam a desconstruir a ideia de que a produção no campo do ensino de sociologia no Brasil é incipiente.

O aumento das produções a partir dos anos 2000, em particular a partir de 2008, refletem a realidade da implantação de um currículo para o ensino médio que torna a sociologia uma disciplina obrigatória. Tal fato decorre de uma mobilização de grupos de pesquisa e de movimentos políticos que se envolveram diretamente na luta pela inclusão desta disciplina na escola básica.

No que se refere as categorias temáticas, ressaltamos a predominância dos estudos que tiveram o foco no currículo e na formação de professores, respectivamente. A primeira categoria tem uma relação direta como a consolidação da sociologia como um saber escolar e mobiliza os pesquisadores na busca por uma compreensão de qual o seu papel no ensino médio e que conteúdos ensinar para os jovens. A segunda, por sua vez, se relaciona a como os professores de sociologia vem sendo formados nas instituições de ensino superior, fazendo com que questões acerca da valorização da licenciatura e a sua relação com o bacharelado seja colocada em questão, no sentido de superar a histórica dicotomia entre uma e outra habilitação.

Nos chamou atenção o pouco volume de trabalhos nas categorias que se relacionam mais diretamente a atuação do professor em sala de aula. Encontramos apenas quatro trabalhos que enfocavam aspectos metodológicos do ensino de sociologia. Esse contexto demonstra a necessidade de ampliar o número de pesquisas que tem como objetivo problematizar a formação dos professores de sociologia e a sua prática pedagógica. Essas duas temáticas se configuram, hoje, 
como grandes desafios não apenas para os pesquisadores do campo da Educação e das Ciências Sociais, mas também, para professores que estão em atividade nas escolas públicas e privadas de todo o país, visto que as experiências acumuladas em sala de aula são importantes referenciais para se pensar novas políticas em relação à formação inicial e continuada desses docentes.

Apesar das pesquisas do tipo estado da arte sofrem críticas em relação ao seu alcance, por se valerem, muitas vezes, de uma leitura parcial dos trabalhos, concordamos com Handfas e Maçaira (2014), quando essas autoras afirmam que,

sua pertinência se dá pela necessidade de conhecermos a trajetória de um campo de estudos, cuja produção de conhecimento cresce conforme o debate sobre o retorno da sociologia nos currículos escolares se identifica no início da década de 2000. Entendemos que essa produção de tendência crescente necessita ser mapeada e analisada, de modo a tornar conhecido um campo que ainda precisa ser caracterizado (HANDFAS, MAÇAIRA, 2014, p.46).

Por hora é o que podemos apontar como resultados e considerações parciais deste estudo. Esperamos, com isso, poder (re)escrever a história da institucionalização da sociologia como saber escolar no contexto brasileiro.

\section{Referências bibliográficas}

ANDRÉ, Marli et al. Estado da Arte da formação de professores no Brasil. Educação e Sociedade, Campinas, v. XX, n. 68, p. 301-309, dez. 1999.

BRASIL. Orientações curriculares para o ensino médio: Ciências humanas e suas tecnologias / Secretaria de Educação Básica. - Brasília: Ministério da Educação, Secretaria de Educação Básica, 2006.

FRIGOTTO, Gaudêncio; CIAVATTA, Maria. O estado-da-arte das políticas de expansão do ensino médio técnico nos anos 1980 e de fragmentação da educação profissional nos anos 1990. In: (Orgs.). A formação do cidadão produtivo: a cultura do mercado no ensino médio técnico. Brasília: INEP, 2006. p. 71-96. HANDFAS, A. O estado da arte do ensino de sociologia na educação básica: um 
levantamento preliminar da produção acadêmica. Revista Inter-legere, 9:386400. 2011.

HANDFAS, A; MAÇAIRA, J. P. O estado da arte da produção científica sobre o ensino de sociologia na educação básica. BIB. Revista Brasileira de Informação Bibliográfica em Ciências Sociais, São Paulo, v.2, n. 74, 2014, p. 45-61.

MORAES, A. C. Licenciatura em Ciências Sociais e Sociologia. Tempo Social. São Paulo: Depto. Sociologia - USP. v.15, n. 1, p. 5-20. Maio de 2003.

OLIVEIRA, Amurabi. O Currículo de Sociologia na Escola: um campo em construção (e disputa). Revista Espaço do Currículo, v. 6, n. 2, 2013.

SILVA, I. F. Os estudos sobre o ensino de sociologia no Brasil: as possibilidades de (re)construção de uma temática legítima para o campo científico. Mimeo. 2 